\title{
A ASSOCIAÇÃO NACIONAL DE HISTÓRIA: ANPUH E O ENSINO DE HISTÓRIA ${ }^{1}$ \\ THE ASSOCIAÇÃO NACIONAL DE HISTÓRIA: ANPUH AND THE HISTORY TEACHING
}

\author{
Iraíde Marques de Freitas Barreiro² \\ Ana Paula Giavara ${ }^{3}$
}

\begin{abstract}
RESUMO: Ao longo de sua trajetória, a Associação Nacional de História - ANPUH, fundada em 1961 por um grupo de professores universitários, exerceu um importante papel propositivo em relação à História como curso de nível superior. Nos anos de 1970, pulverizou-se por meio de Núcleos Regionais em muitos estados brasileiros, acrescentando à sua pauta de discussão os assuntos relacionados à disciplina nos $1^{\circ}$ e $2^{\circ}$ graus de ensino. Paulatinamente, o corpo de associados também se expandiu, passando a admitir estudantes e professores secundaristas, além de catedráticos de outras áreas das Ciências Humanas. De tal forma, o objetivo desta investigação concentra-se em delinear a trajetória de surgimento fortalecimento da entidade, entre as décadas de 1960 a 1990. Partindo da emergência da ANPUH nacional em direção à atuação de seu Núcleo Regional de São Paulo - NRSP, foram destacadas as condições contextuais e internas que fizeram com que a História como disciplina escolar, conjuntamente à História acadêmica, se tornasse o centro das discussões anpuhanas.
\end{abstract}

Palavras-chave: Associação Nacional de história - ANPUH. Ensino de história. Políticas educacionais. Disciplina escolar. Estado de São Paulo.

\footnotetext{
ABSTRACT: Throughout its history, the Associação Nacional de História - ANPUH, founded in 1961 by a group of university professors, has always exercised an important combative role in the claim of History as a higher level course. In the 1970s, it has spread through Regional Centers in many Brazilian states, adding to the discussion subjects related to the discipline in the 1st and 2nd grades of education. Gradually, the membership team also expanded, admitting students, high school teachers and university professors from other areas of the Human Sciences. Thus, the objective of this research is to delineate the trajectory of the emergence and expansion of this Association, from the 1960s to the 1990s. Starting from the historical process of the emergence of the Associação Nacional de

${ }^{1}$ Fomento: Coordenação de Aperfeiçoamento de Pessoal de Nível Superior - CAPES.

2 Professora Assistente do Departamento de Educação da Faculdade de Ciências e Letras de Assis e da Pós-Graduação na Faculdade de Filosofia e Ciências de Marília. Doutora em Educação pela Universidade de São Paulo.

3 Doutoranda do Programa de Pós-graduação em Educação da Faculdade de Filosofia e Ciências de Marília.
} 
História, as well as the activities of the Regional Center of São Paulo, it will be highlighted here the conjunctural and internal conditions that made the discipline of History of the basic school and academic History, the center of the ANPUH's discussions.

Keywords: Associação Nacional de História - ANPUH. History teaching. Educational policies. History discipline. State of São Paulo.

\section{Introdução}

Fundada em 1961, por um grupo de professores universitários, a então chamada Associação dos Professores Universitários de História $\mathrm{APUH}^{4}$ teve como uma de suas primeiras pautas de discussão a influência do modelo econômico taylorista nas reformas educacionais em curso. Após o golpe de 1964, posicionou-se contrária à reestruturação do ensino de acordo com a lógica empresarial. Além de desempenhar um importante papel combativo, a entidade teve uma atuação propositiva no debate que envolveu a Reforma Universitária de 1968.

Com o passar dos anos, a Associação vislumbrou o alargamento de suas bases, sendo composta, já nos anos de 1970, por Núcleos Regionais em vinte Estados brasileiros. Sem abandonar sua problemática elementar a História no ensino superior, a Associação Nacional de História - ANPUH acrescentou à sua pauta de discussão os assuntos relacionados à disciplina nas escolas de $1^{\circ}$ e $2^{\circ}$ graus. Paulatinamente, o corpo de associados também se expandiu, passando a admitir estudantes e professores secundaristas, além de catedráticos de outras áreas das Ciências Humanas, o que fez com que até mesmo os desígnios de seu Estatuto fossem alterados nos anos de 1990.

Considerando a importância desse conclave de historiadores, realizado nacionalmente há quase seis décadas, esta investigação

\footnotetext{
${ }^{4}$ A partir de seu IV Simpósio, a entidade ganhou o título de Associação Nacional dos Professores Universitários de História, devido a sua abrangência territorial. Tempos mais tarde, durante a realização do VI conclave, decidiu-se pela mudança também de seu acrônico para ANPUH (SIMPÓSIO NACIONAL DE PROFESSORES UNIVERSITÁRIOS DE HISTÓRIA, 1973, p. 8).
} 
concentra-se em delinear a trajetória de surgimento e manutenção da entidade entre as décadas de 1960 a 1990. Partindo da emergência da Associação Nacional em direção à atuação do Núcleo Regional de São Paulo, serão aqui destacadas as condições contextuais e internas que fizeram com que a História como disciplina escolar, ao lado da História acadêmica, se tornasse o centro das discussões anpuhanas.

Para vislumbrar esse percurso, compõem o corpus documental desta investigação algumas publicações periódicas que circularam entre os associados no período em questão, como o Boletim Informativo e do Boletim do Historiador, sendo a primeira editada pela ANPUH nacional e a segunda pela ANPUH-SP; determinados exemplares de Anais de Simpósios nacionais, bem como alguns números da Revista Brasileira de História, publicação científica divulgada pela Associação desde 1981.

As dificuldades em se trabalhar com fontes periódicas estiveram circunscritas à composição da série completa do corpus selecionado, bem como a suas condições de conservação. Mesmo se tratando de uma Associação de historiadores, a ANPUH (nacional e paulista) não realizou a organização de seus documentos, o que pressupõe que parte de seu percurso já não possa ser delineado. As edições disponíveis foram angariadas em diferentes locais, como no arquivo pessoal da professora Helenice Ciampi, da PUC-SP, no endereço da própria Associação, localizado na Faculdade de Filosofia, Letras e Ciências Humanas - FFLCH da Universidade de São Paulo - USP e no Centro de Apoio à Pesquisa em História - CAPH da mesma universidade, especificamente no arquivo pessoal do Prof. Eurípedes Simões de Paula.

Finalmente, a análise da imprensa periódica se fará mediante a identificação das relações entre os objetivos do grupo editor e o público que visava atingir. Estes impressos são considerados, a um só tempo, como fonte e objeto nesta investigação e revelam-se como um "espaço de sociabilidade" entre os grupos. Representantes do discurso e do posicionamento de um grupo de intelectuais em relação ao ensino de 
História, estas publicações, longe de uma pretensa neutralidade, podem revelar detalhes da História da Associação (DE LUCA, 2014).

\section{A História da Associação: das linhas de seu boletim à reforma universitária de 1968}

Apresentando abrangência nacional, a primeira publicação da então chamada APUH - Associação dos Professores Universitários de História denominou-se Boletim Informativo ${ }^{5}$ e foi editada em Marília, entre os meses de janeiro-outubro de 1962. Fruto das discussões do I Simpósio de Professores de História do Ensino Superior, realizado na cidade de Marília, em 1961, este periódico constituiu-se como veículo pioneiro de comunicação entre os pares associados.

Em uma das moções contidas nos Anais do referenciado Simpósio, José Roberto do Amaral Lapa, catedrático da Faculdade de Filosofia sede do evento, ressaltou a falta de diálogo entre os docentes universitários de História, reivindicando a criação de uma entidade que pudesse agrupá-los:

Considerado o isolamento em que trabalham os professores universitários de História, uns em relação aos outros. Considerando a importância que, em nossos dias, assume o diálogo para o cientista. Considerando o êxito que, no gênero, têm logrado outras iniciativas, submeto à apreciação desta Mesa Redonda, a proposta da criação de uma entidade que possa congregar os professores universitários de História." Moção assinada por José Roberto do Amaral Lapa que marca o nascimento da primeira sociedade de professores de História de nível superior, em nosso país (SIMPÓSIO DE PROFESSÔRES DE HISTÓRIA DO ENSINO SUPERIOR EM 1961, 1962).

Frente à necessidade de discutir questões próprias do campo historiográfico em uma época de profundas transformações na universidade brasileira, a APUH emergiu do Simpósio de 1961 e seu Boletim deveria conter manifestos, avisos e informações sobre os eventos da Associação,

\footnotetext{
5 "Boletins" são publicações de caráter essencialmente informativo, normalmente destinados à circulação interna ou à divulgação pública, em intervalos mais ou menos regulares, de entidades de classe ou de repartições governamentais e privadas (BOLETINS, 2004).
} 
sobretudo, seus conclaves bianuais, além de compilações bibliográficas das recentes pesquisas, editais para concursos na área de História e textos editoriais, o que reafirmaria seu papel informativo.

O grupo editor ${ }^{6}$ apontou a importância desta publicação sob o título "Êste Boletim", impresso na capa do primeiro exemplar:

Criada, consoante o próprio enunciado da moção que a inspirou, para estabelecer freqüente e profícuo diálogo entre os professores universitários de História, que até antão vinham trabalhando em geral isolamento, a APUH dá agora, com lançamento dêste Boletim, um dos primeiros passos para a concretização dêsse diálogo. Terá o Boletim caráter exclusivamente informativo, não se destinando, portanto, à publicação de trabalhos, discursos ou conferência dos associados. O seu principal escopo residirá na divulgação do noticiário de interêsse da Associação, bem como de tudo quanto se relacione com a atividade docente e de pesquisa dos professores universitários de História?.

Não se encontraram referenciados nesta primeira edição do Boletim Informativo os recursos financeiros utilizados em sua impressão e distribuição. O que se sabe, entretanto, é que, ao longo dos anos, a publicação informativa da Associação passou por várias remodelações, sendo cessada e retomada algumas vezes. Em 1993, por exemplo, um novo periódico foi fundado sob o título Boletim da ANPUH. A dificuldade em manter a periodicidade de uma publicação informativa foi expressa pelos editores:

Por várias vezes, em várias gestões da Diretoria Nacional da ANPUH, ventilou-se a necessidade de um mecanismo de comunicação entre os associados. Houve ensaios. Vamos tentar mais uma vez. Temos a certeza de que, com a

6 Compuseram a primeira diretoria da ANPUH, em outubro de 1961. Presidente: Prof. Eremildo Luís Viana (Faculdade de Filosofia da Universidade do Brasil); Vice-Presidente: Profa. Cecília Maria Westphalen (Faculdade de Filosofia da Universidade do Paraná); Secretário-Geral: Prof. Sérgio Buarque de Holanda (Faculdade de Filosofia da Universidade de São Paulo); 10 Secretário: Profa. Alice Piffer Canabrava (Faculdade de Ciências Econômicas de Administrativas da Universidade de São Paulo); 20 Secretário: Prof. Jorge Calmon (Faculdade de Filosofia da Universidade da Bahia); 10 Tesoureiro: Prof. Antonio Camilo de Faria Alvim (Faculdade de Filosofia da Universidade de Minas Gerais); 20 Tesoureiro: Prof. Armando Souto Maior (Faculdade de Filosofia da Universidade do Recife) e Diretor de Publicações: Prof. José Roberto do Amaral Lapa (Faculdade de Filosofia, Ciências e Letras de Marília). (BOLETIM INFORMATIVO, 1962, n. 1. p. 3).

7 Associação dos Professores Universitários de História. Boletim Informativo, Marília, jan./out. 1962, ano 1, n. 1. p. 1. Disponível em: CAPH - Centro de Apoio à Pesquisa em História Sérgio Buarque de Holanda. CPH/DH - Projeto Memória da FFCL/ FFLCH-USP. Arquivo do Prof. Dr. Eurípedes Simões de Paula. 
colaboração de todos, e de modo especial das Diretorias dos Núcleos regionais, conseguiremos manter este Boletim por mais tempo. Simples, pequeno, despretensioso, mas que se constitua naquele gesto de amizade acadêmico-científica que de alguma maneira nos une. Será um Boletim trimestral, previsto para março - junho - setembro - dezembro, contendo seções com as quais se pretende cobrir as principais preocupações da Associação: Informes Gerais da ANPUH Nacional - Informes aos Núcleos e dos Núcleos Projeto de Pós-Graduação - Ensino - Revista Brasileira de História. Ficamos aguardando a colaboração que nos permita a continuidade deste propósito (BOLETIM DA ANPUH, n. 1, 1993, p. 1).

Em 1976, José Roberto do Amaral Lapa, um dos sócios fundadores da entidade, justificou a limitação da ANPUH em sua primeira década de existência pela insuficiência de recursos, já que não havia subsídios governamentais, tampouco auxílio das faculdades ou associados (LAPA, 1976, p. 186), o que sobrecarregava a atuação dos membros da presidência e secretaria. Além disso, a escassez orçamentária também foi responsável pela periodicidade irregular e distribuição geográfica ineficaz dos encontros, de modo que as regiões mais necessitadas, do ponto de vista de Lapa, não participavam das discussões.

O Boletim Informativo também tornou público o Estatuto da Associação dos Professores Universitários de História, com capítulos referentes a objetivos, associados, administração, reuniões, publicações, patrimônios, núcleos regionais, disposições gerais e disposições transitórias, além dos nomes que aderiram à Associação, em nível nacional, até setembro de 1962, alcançando um total de cento e quarenta e três membros. Entre seus objetivos, figuravam: "a) o aperfeiçoamento do ensino de História em nível superior; b) o estudo, a pesquisa e a divulgação de assuntos de História e c) a defesa das fontes e manifestações culturais de interêsse dos estudos históricos" (LAPA, 1976, p. 3).

No texto desse Estatuto, não eram importantes os assuntos concernentes ao ensino nos $1^{\circ}$ e $2^{\circ}$ graus, condição a ser revertida nos debates da Associação em meados dos anos de 1970. Nascida com o intuito de discutir questões próprias do ensino superior, a ANPUH, incialmente, concentrou esforços para pensar a expansão da universidade brasileira 
sobre os pilares do autogoverno e da qualidade. Na esteira dessas transformações, o curso de graduação em História carecia de incentivo à pesquisa, além de remodelações em seu padrão pedagógico, administrativo e curricular.

A grande inovação trazida pelo Estatuto da Associação residiu no fato de que, pela primeira vez, desde a década de 1930 - quando os cursos de História foram criados em Institutos e Faculdades de Filosofia, a disciplina acadêmica lutou por autonomia, por espaço enquanto ciência necessitária de atributos teóricos e metodológicos, o que implicava a necessidade de uma formação universitária mais complexa e tonificada nos âmbitos profissional e docente.

Imbuído em remodelar a universidade brasileira para atender aos anseios de uma sociedade em transformação, o I Simpósio da ANPUH repercutiu a urgência de se fazer a Reforma Universitária, ao ponto de influenciar, anos mais tarde, os órgãos colegiados de algumas Instituições (CANABRAVA, 1981). Postas as condições conjunturais em que se encontrava o Brasil na década de 1960 - tais como o crescimento populacional, o processo de urbanização, o aumento do poder aquisitivo da classe média, além do emergente envolvimento do capital estrangeiro no país - a palavra de ordem era "reforma",

[...] o reencontro da sintonia entre a universidade e a realidade social para se não frustrarem os objetivos daquela. Impunha-se modelar de novo a estrutura das universidades, de modo a conferir-lhes maior flexibilidade administrativa, curricular e docente, enfim, rever o elenco das disciplinas, alertar as normas do recrutamento do corpo docente e da ascensão dos degraus da carreira acadêmica, conceder real importância à pesquisa, como atividade básica da universidade, que dá a medida do seu "status" no cenário científico internacional (CANABRAVA, 1981, p. 2).

De acordo com tais desígnios, as conclusões a que chegaram os participantes do I Simpósio estiveram relacionadas, sobretudo, à necessidade de desdobramento de cursos conjugados (como História e Geografia) em Faculdades de Filosofia e de valorização da História do Brasil e da História Regional. Destacaram-se, também, problemas de ordem 
profissional e didática, bem como o intuito de reorganizar as periodizações históricas. Urgia que se fizesse uma reestruturação curricular nos cursos de graduação e pós-graduação, com foco na inserção de disciplinas de natureza teórica e metodológica (SIMPÓSIO DE PROFESSÔRES DE HISTÓRIA DO ENSINO SUPERIOR EM 1961, 1962)

Contudo, os anseios dos participantes do Simpósio não puderam ser acatados pela Reforma empreendida pelo governo militar, em 1968. No contexto da Guerra Fria, em que Estados Unidos e União Soviética disputavam zonas de influência mundialmente, os militares alinharam a Reforma Universitária ao modelo capitalista norte-americano, impondo economia e eficiência operacional às instituições de ensino. Assinado em 1966, o acordo entre o Ministério da Educação - MEC e a United States Agency for International Development - USAID, tinha como objetivo a renovação da universidade com vistas à superação das heranças de um passado elitista e provinciano. Para os Estados Unidos, o acordo significou a garantia da influência econômica e cultural no Brasil. ${ }^{8}$

Criada na década de 1930, a universidade brasileira possuía um caráter bacharelesco de formação que incitava a reprodução de um conhecimento predominantemente eurocêntrico. A pesquisa científica não encontrava nessas instituições terreno fértil, sendo as aulas essencialmente livrescas e desprovidas de espaço para reflexões críticas. Ademais, a contratação de docentes e servidores atendia a interesses clientelistas. "Abertas aparentemente a todos, as universidades, de fato, recrutavam alunos entre as categorias privilegiadas. No dizer de Lévy-Strauss, até

\footnotetext{
${ }^{8}$ No contexto da Guerra fria, ante a ameaça comunista "[...] os Estados Unidos procuraram estreitar os laços com os países da América Latina, mediante projetos de desenvolvimento patrocinados pelo Inter-American Development Bank (Banco Interamericano de Desenvolvimento), criado em 1957, e pela Aliança para o Progresso, de iniciativa do presidente John Kennedy. A contrapartida do auxílio econômico e cultural era a assistência militar com a qual os Estados Unidos pretendiam garantir a segurança do hemisfério. Com esse objetivo, a Agency for International Development (AID) financiava, por exemplo, o treinamento de policiais latino-americanos na Carolina do Norte, No Forte Bragg e na Escola das Américas, no Panamá. Consciente da força das ideologias, o governo americano empenhara-se em expandir a influência cultural dos Estados Unidos. É a partir desse quadro internacional que se podem entender os vários convênios que resultaram em chamado projeto MEC-Usaid (COSTA, 2004, p. 37).
} 
então, a cultura fora uma distração dos ricos. Com raras exceções, a universidade era expressão dessa realidade" (COSTA, 2004, p. 38-39).

Sob o pretexto de flexibilização e racionalização administrativa do ensino superior, a reforma assumiu uma lógica empresarial, atrelada à produção capitalista e à empresa privada. Faziam-se necessárias "[...] a extinção do sistema de cátedras, a introdução da organização departamental; a divisão do currículo escolar em dois ciclos, um básico e outro profissionalizante, integração das atividades de ensino e pesquisa e ênfase na pós-gradução" (GERMANO, 2011. p.118-119). Na atmosfera da parceria MEC-USAID, o governo militar veiculava

[...] a universidade como empresa, a valorização da iniciativa privada em detrimento da participação do Estado, a substituição do ideal de gratitude do ensino superior pelo da lucratividade, a ênfase na formação tecnológica em detrimento da formação humanística e a subordinação dos ideais de liberdade de expressão e de cátedra ao ideal de segurança nacional definido nos termos da guerra fria (COSTA, 2004, p. 39).

O impacto da reforma nos currículos da graduação foi sentido pelas três principais universidades paulistas da época - Pontifícia Universidade Católica - PUC, Universidade Estadual de Campinas - UNICAMP e Universidade de São Paulo - USP. Houve determinante separação entre o bacharelado e a licenciatura nos níveis estrutural, acadêmico e pedagógico. Na PUC-SP, por exemplo, o curso de História passou a constituir-se em três ciclos: o básico, o profissional e a especialização científica ou pósgraduação, sendo o primeiro mais direcionado à docência nos $1^{\circ}$ e $2^{\circ}$ graus e o último à pesquisa histórica (CIAMPI, 2000).

No decorrer dos anos de 1970, por força da própria reforma, o curso de História caracterizou-se pela separação entre o "fazer historiográfico" e o "ensinar / transmitir" os conhecimentos históricos. De acordo com essa lógica de formação, não era necessário que os professores primários e secundários refletissem historicamente sobre a realidade vivida, sendo vulgarizadores do conhecimento. Vistos como estruturas distintas e rigidamente compartimentalizadas, também não havia diálogo entre os cursos de graduação e pós-graduação nos Departamentos de História. 
Enquanto os graduandos eram conduzidos para a docência, os pósgraduandos concentravam-se nos trabalhos investigativos, estes sim, necessitários de reflexão e rigor científico.

Às licenciaturas, estava relegado um conhecimento despolitizado, fragmentado e especializado, de modo que as disciplinas de ensino, como Didática e Práticas Pedagógicas, eram pormenorizadas. "Daí a didática se torna estática, não indaga a realidade dos alunos com os quais vai lidar [...]" (FENELON, 1985, p. 27). Por outro lado, o pesquisador, produtor do conhecimento histórico, teria uma formação mais ampla que envolveria conhecimentos de natureza teórica e metodológica, em disciplinas de Introdução, Metodologia e Teoria ou Historiografia. Aprofunda-se, nesse contexto, a dicotomia entre a "história pensada" e a "história ensinada" (CIAMPI, 2000). Até meados dos anos de 1980, nos cursos de graduação,

\begin{abstract}
As discussões sobre os aspectos metodológicos e teóricos são reservadas aos Cursos de Introdução, Metodologia e Teoria ou Historiografia, quando existem nos currículos, e os professores de outras disciplinas estão eximidos da discussão metodológica, pois isto é assunto de disciplina específica e seria até considerado 'invasão de área'. Eles são assim os professores da 'História propriamente dita', ou seja, lidam com o processo histórico, só que cada um a sua maneira, sem realizar diálogo ou esclarecimento sobre o sentido e o significado de sua posição, do direcionamento de seu curso para tal abordagem e não outra (FENELON, 1985, p. 28).
\end{abstract}

Diante de tais condições conjunturais, a ANPUH inaugurou, em suas primeiras décadas de atuação, a luta pelo fim da dicotomia entre licenciaturas e bacharelados, o que conferiria maior cientificidade ao trabalho de docentes e pesquisadores, pois o déficit de formação era causado, inclusive, pela falta de estudos relacionados à manipulação e análise de fontes historiográficas nos cursos de História. Até meados da década de 1980, o panorama de formação do historiador encontrava-se da seguinte maneira:

Grande parte dos nossos alunos são formados em História, mas não são capazes de elaborar uma problemática de pesquisa. Tiveram contatos mínimos com qualquer tipo documentação e não aprenderam a trabalhar com ela, raramente freqüentaram qualquer tipo de Arquivo ou foram em busca de outras fontes de investigação, aprendendo a 
questioná-las na forma como aprecem ou foram encobertas, no conteúdo do que dizem, na situação de testemunhos de que são origem. Isto não se faz, em verdade, porque a maioria dos professores muitas vezes jamais realizou este tipo de trabalho e tem sobre sua tarefa de ensino uma concepção que não difere da idéia do repassador de conhecimentos e de informações. (FENELON, 1985, p. 30).

Nesse contexto, as atividades de pesquisa, um dos pilares de sustentação da qualidade do ensino superior, não faziam parte do cotidiano educacional dos alunos de graduação, tampouco dos professores das Faculdades de Filosofia. Quando desenvolvidas, as investigações não abrangiam a coletividade, tampouco atendiam às necessidades sociais, e possuíam, essencialmente, cunho acadêmico. Por outro lado, revelavam-se "[...] aleatórias e avocadas por docentes como imposição para galgar os degraus da carreira universitária, sem desenvolver-se como atividade permanente." (CANABRAVA, 1981, p. 7)

Buscando reverter esse quadro conjuntural, a ANPUH surgiu e se fortaleceu, legando, para os encontros futuros, um crescente enriquecimento da experiência universitária e a elevação do padrão científico do trabalho do professor. Desde sua primeira reunião, em 1961, consagrou-se como um espaço de renovação no pensamento histórico brasileiro, posto o intercâmbio de ideias entre professores do país e do exterior.

\section{Da História acadêmica à História disciplinar}

A abrangência da ANPUH foi renovada e ampliada a cada novo Simpósio. Paulatinamente, seu corpo de associados expandiu-se para além dos professores universitários, chegando a atingir, no ano de 1973, mil associados (SIMPÓSIO NACIONAL DE PROFESSORES UNIVERSITÁRIOS DE HISTÓRIA, 1973). Também reivindicavam espaço para discussão nos conclaves profissionais historiadores de arquivos e museus, graduandos e pós-graduandos (no início, aceitos apenas facultativamente), além de 
catedráticos de outras áreas das Ciências Humanas. A presença de estudantes como ouvintes do VI Simpósio da Associação, realizado no ano de 1973, na cidade de Goiânia, mereceu destaque em seus Anais:

[...] justifica-se refletir sôbre os aspectos positivos da presença dos estudantes, quase igual a dos professôres (universitários e secundários). Eles: alunos hoje, professôres amanhã, facultam supor a receptividade da tese exposta pelo presidente da ANPUH na sessão de abertura do Simpósio: "a escolaridade pressupõe o binômio professor-aluno, alunoprofessor, numa tentativa de compreensão e diálogo que, vêzes por outra, é conseguido". Eles que, pela sua avalanche inesperada, ocasionaram problemas de acomodação para seus colegas goianos. Eles que, pelo comportamento não se tem notícia de nada que os desabone, pela atenção com que acompanharam as sessões de estudo, provaram e comprovaram que os nossos estudantes de História sabem distinguir o que é autêntico e conseqüentemente - válido e promissor (SIMPÓSIO NACIONAL DE PROFESSORES UNIVERSITÁRIOS DE HISTÓRIA, 1973).

Apesar dessa ampla participação, apenas no IX Simpósio Nacional, realizado na cidade de Florianópolis-SC, em 1977, foi permitida a efetiva participação de estudantes e de professores de $1^{\circ}$ e $2^{\circ}$ graus. Contudo, em notas introdutórias aos Anais desse Simpósio, a professora Maria Regina Simões de Paula expressou a incerteza quanto às vantagens e desvantagens dessa aceitação, o que necessariamente implicaria em adequações no Estatuto e nome da entidade:

Porquanto ficou estendido a todos estudantes e professores desde que regularmente inscritos nos Simpósios o direito de apresentar comunicações e participar dos debates nas sessões dos mesmos. Excluído, apenas o direito de voto na Assembléia Geral, privativo dos professores universitários de História. Perguntar-se-ia se o posicionamento assumido pela maioria dos associados presentes no Plenário de Florianópolis, foi um bem ou um mal para a entidade adolescente? Avanço ou retrocesso? E a sigla ANPUH? Ponto de partida para uma imperativa readequação? - Indagações que, provavelmente irão encontrar respostas no X Simpósio em Niterói (SIMPÓSIO NACIONAL DA ASSOCIAÇÃO DOS PROFESSORES UNIVERSITÁRIOS DE HISTÓRI, 1979, p. 17).

Desse momento em diante, a Associação passou a desempenhar "[...] o papel de escola, no seu sentido legítimo, a congregar licenciados e graduandos para o convívio com métodos, técnicas e interpretações que 
germinam nas fronteiras avançadas do conhecimento histórico." (CANABRAVA, 1981, p. 4). Como previsto no Simpósio de 1977, esse alargamento culminou, em 1993, na reelaboração de alguns pontos do Estatuto de 1962 e na mudança de denominação da Associação, preservando-se, contudo, o acrônico - ANPUH. Aprovada na Assembleia Geral Ordinária, realizada no XVII Simpósio Nacional de História,

[...] a ANPUH passa a ser chamada de Associação Nacional de História, denominação mais curta, porém mais abrangente que a anterior, pois considera o contingente de historiadores que não professores universitários mas que tem engrossado os quadros da Associação nos últimos anos Boletim do Historiador. (BOLETIM DO HISTORIADOR, n. 8, 1993, p. 1)

Superada a urgência dos debates acerca da Reforma Universitária, a temática dos Simpósios passou por diversas transições. Por influência do alargamento da base de sócios, ocorreu também a ampliação dos debates para outros níveis de educação. Nos anos de 1970, o foco das discussões sobre ensino foram as políticas educacionais para os $1^{0}$ e $2^{\circ}$ graus. À semelhança da Reforma Universitária, as diretrizes educacionais militares, para tais níveis, revelaram-se limitantes da autonomia dos sujeitos educacionais e supressoras dos saberes históricos.

Em um contexto de plena industrialização e exacerbado autoritarismo político, a Lei 5.692/71 teve a função de conferir legitimidade ao governo militar, garantindo sua manutenção. Esta diretriz logrou vasta aceitação entre as camadas populares, sobretudo, pela ampliação da oferta educacional. Assim como sua antecessora, a reforma educacional de 1971 procurou atender aos interesses do capital estrangeiro, pois buscou absorver a força produtiva, e regular o mercado de trabalho, por meio de duas medidas essenciais: no ensino de $1^{0}$ grau, a ampliação da escolaridade obrigatória de quatro para oito anos e, no $2^{\circ}$ grau, a disseminação do ensino profissionalizante (GERMANO, 2011).

No campo do ensino de História, a Lei 5.692/71 preconizou a fusão da História e da Geografia em outro componente curricular a ser ministrado nos dois níveis de ensino: os Estudos Sociais. As disciplinas de Filosofia, 
Psicologia e Sociologia foram sumariamente excluídas dos currículos do 20 grau. Ao lado de disciplinas como Educação Moral e Cívica - EMC e Organização Social e Política do Brasil - OSPB, os Estudos Sociais serviram como instrumentos de normalização e controle das massas trabalhadoras (BITTENCOURT, 2009). Com estas reformulações curriculares, o Estado militar pretendia:

[...] debilitar o ensino de História, pela rejeição de sua individualidade. O propósito está latente no texto legal com a encampação do ensino da História e da Geografia no núcleo compósito de disciplinas designado por Estudos Sociais. Sob o pretexto de promover "a integração de estudos", cujo mérito é aceito, ignoram-se os métodos e objetivos próprios, a personalidade do campo científico, próprios a cada disciplina e, no caso específico da História, sua importância singular para a consciência coletiva (CANABRAVA, 1981, p. 8).

As discussões sobre os impactos dessa reforma estiveram presentes no VII Simpósio da ANPUH, realizado na cidade de Belo Horizonte, em 1973, o que consubstancia seu posicionamento de defesa ao ensino de História. Em notícia publicada no Diário de Minas, Eurípedes Simões de Paula, então presidente da Associação, afirmou: "É ponto pacífico a manifestação contrária aos Estudos Sociais que, da maneira como estão sendo ministrados, não ajudam a ninguém, seja aluno ou professor" (DIÁRIO DE MINAS, 1 set 1973, p. A1) ${ }^{9}$. Entre outros pontos, os participantes do Simpósio também discutiram os seguintes problemas:

[...] baixa remuneração, diminuição da carga horária das aulas e falta de condições didáticas que estão contribuindo "para a frustração dos professores e conseqüente prejuízo para os alunos". Paralelamente ao Simpósio, os estudantes estão realizando reuniões para discutir diversos problemas do curso de História. (DIÁRIO DE MINAS, 5 set 1973, p. 1)

O debate sobre a necessidade de reverter a instituição dos Estudos Sociais estendeu-se por toda a década de 1970, adentrando

\footnotetext{
${ }^{9}$ Recortes de Jornal. Diário de Minas 05/09/1973. Disponível em: CAPH - Centro de Apoio à Pesquisa em História Sérgio Buarque de Holanda. CPH/DH - Projeto Memória da FFCL/ FFLCH-USP. Arquivo do Prof. Dr. Eurípedes Simões de Paula.
} 
os anos de 1980. Em 1981, por exemplo, durante seu XI Simpósio, a Associação discutia a responsabilidade social e política da disciplina e os desafios da tarefa de apresentar a História como um conhecimento produzido, e não como descrição perfeita do real. Para tanto, era preciso que a disciplina recobrasse a propriedade de seus saberes. De maneira geral, recusava-se a visão da escola e do ensino como ferramentas de manutenção do regime e como reprodutores do conhecimento conveniente às classes dominantes (CORDEIRO, 2000)

As iniciativas de reformulação do ensino de História eram de cunho individual e coletivo e partiam de professores - que formulavam projetos didáticos alternativos, das universidades - que ofereciam contribuições provenientes dos mais recentes estudos historiográficos e educacionais e do próprio Estado que, pressionado pelas reivindicações sociais por mudanças, passou a divulgar propostas curriculares mais pertinentes à nova organização política nacional. Ultrapassando esses limites, também participou das discussões a mídia, representada, principalmente, pela imprensa escrita (CORDEIRO, 2000; FONSECA, 2006).

Diante de tais circunstâncias, em 1981, a Revista Brasileira de História, órgão criado pela ANPUH em comemoração ao seu vigésimo aniversário, veio a desempenhar importante função em âmbito nacional e internacional. Seu principal escopo era dar visibilidade às pesquisas científicas na área, tendo sido cessada a publicação dos Anais dos Simpósios da ANPUH em $1977^{10}$. Em ata que registra a Fundação da Revista, Raquel Glazer, então secretária, observou que

\footnotetext{
10 Os Anais "[...] compreendem dezenove volumes, designados pelo tema central da seção de pesquisa e englobam os trabalhos de nove Simpósios, de 1961 a 1977. A partir do volume de 1965, consagrado ao III Simpósio realizado em Franca SP, o Prof. Eurípedes Simões de Paula empenhou-se em publicá-los regularmente. Do muito que sua dedicação e entusiasmo deram à associação no período de doze anos (1965/1977) em que ocupou a presidência, possivelmente a obra mais importante seja esta, o registro dos trabalhos da entidade, na coletânea impressa" (CANABRAVA, 1981, p. 9).
} 
os Anais possuíam um ônus muito elevado para as possibilidades orçamentárias da entidade. 0 mesmo documento trouxe referenciada a decisão por uma periodicidade de dois números anuais que seriam subvencionados pelos sócios e, posteriormente, comercializados (GLEZER, 1981).

O quadro a seguir retrata a crescente importância que o ensino de História alcançou nas páginas deste periódico, sobretudo em meados da década de 1980.

Quadro 1 - Textos Publicados na Revista Brasileira de História

\begin{tabular}{|l|l|l|l|}
\hline \multicolumn{1}{|c|}{ ANO } & \multicolumn{1}{|c|}{$\mathbf{N}^{\mathbf{0}}$} & QUANTIDADE DE TEXTOS & \multicolumn{1}{c|}{ SEÇÃO } \\
\hline 1982 & 03 & 1 artigo & - \\
\hline 1983 & 06 & 1 nota & Noticiário \\
\hline 1984 & 07 & $\begin{array}{l}1 \text { artigo } \\
2 \text { notas }\end{array}$ & $\begin{array}{l}\text { Questões Didáticas } \\
\text { Noticiário }\end{array}$ \\
\hline $1984 / 85$ & $8 / 9$ & 1 nota & Noticiário \\
\hline 1985 & 10 & 3 artigos & Questões Didáticas \\
\hline $1985 / 86$ & 11 & 2 artigos & - \\
\hline 1986 & 12 & 1 artigo & Questões Didáticas \\
\hline $1986 / 87$ & 13 & $\begin{array}{l}2 \text { artigos } \\
1 \text { nota }\end{array}$ & $\begin{array}{l}\text { Ensino } \\
\text { Noticiário }\end{array}$ \\
\hline 1987 & 14 & 4 textos & Polêmica \\
\hline $1987 / 88$ & 15 & $\begin{array}{l}1 \text { artigo } \\
1 \text { comunicação }\end{array}$ & $\begin{array}{l}\text { Ensino } \\
\text { Noticiário }\end{array}$ \\
\hline $1988 / 89$ & 17 & 1 nota & $\begin{array}{l}\text { Artigoticiário } \\
\text { Crítica Bibliográfica }\end{array}$ \\
\hline $1989 / 90$ & 19 & $\begin{array}{l}9 \text { artigos } \\
2 \text { textos }\end{array}$ & \\
\hline
\end{tabular}

Fonte: Cordeiro (2000).

Destaque especial deve ser conferido ao número 19 da Revista Brasileira de História. Coordenada por Marcos Antonio da Silva, entre 1989 e 1990, essa publicação dedicou-se a refletir exclusivamente sobre a História como disciplina escolar. Incorporada em uma série de edições temáticas, teve como título "História em Quadro negro: escola, ensino e aprendizagem". Ao apresentá-la, seu coordenador fez menção a um compósito de "vozes" que ressoavam para a história ensinada. Vozes 
dissonantes, mas que dividiam uma perspectiva comum: "[...] a possibilidade de manter o ensino entre as preocupações teóricas e políticas do profissional e de História." (SILVA, 1990, p. 7).

Respondendo aos anseios de sua época, esta publicação incorporou artigos relacionados à prática, mas também à teoria do ensino da disciplina, concebendo-a como um campo que necessita de investigações científicas e posicionamento político ante a vulgarização e a neutralidade docentes preconizadas pelas políticas educativas. Após duas décadas de discussões em Simpósios, Encontros e publicações da ANPUH, inaugurava-se um espaço para amplas reflexões sobre o ensino de História escolar. Marcos Antonio da Silva anunciou a valorização da História disciplinar e a emergência de um "vozerio da história ensinada". "É preciso ouvi-lo. Ele contribui para se entender porque os quadros-negros, hoje, são verdes" (SILVA, 1990, p. 8).

\section{O Núcleo Regional Paulista e o ensino de História: a ação das diretorias}

Outro ponto que merece destaque no primeiro Estatuto divulgado pela ANPUH, em 1962, se refere à regulamentação de seus Núcleos Regionais $^{11}$, órgãos da Associação nos Estados que teriam autonomia regulamentada por estatutos próprios e diretoria individual. À semelhança da Associação Nacional, os Núcleos Regionais discutiriam questões próprias

\footnotetext{
${ }^{11}$ Criados automaticamente pela aprovação do primeiro Estatuto da ANPUH, em setembro de 1962, já se encontravam fundados onze Núcleos Regionais, dos quais nove estavam instalados e com sua diretoria designada. Tratavam-se dos Núcleos Regionais da Bahia, Goiás, Guanabara, Minas Gerias, Paraná, Pernambuco, Rio de Janeiro, Rio Grande do Norte, Rio Grande do Sul, Santa Catarina e São Paulo. Se outras unidades da federação desejassem criar Núcleos, seria necessário mobilização de seus professores universitários. (BOLETIM INFORMATIVO, 1962, n. 1. p. 6). Em 1963, outros dois núcleos foram criados: "[...] Rio de Janeiro e do Espírito Santo. Os da Paraíba e Santa Catarina estabeleceram-se em 1967, o do Sergipe em 1969, o de Brasília em 1970 e o do Amazonas em 1971, perfazendo uma rede de 16 núcleos filiados ao fim da primeira década de existência. Os núcleos do Ceará, Pará e Mato Grosso pertencem à segunda década, que se arremata agora com a fundação do núcleo regional do Estado do Acre, em novembro do ano findo, completando um total de 20 entidades (CANABRAVA, 1981, p. 5)
} 
da História no ensino superior, sendo considerados os diferentes problemas e peculiaridades locais. O objetivo central seria criar as bases de sustentação do debate a ser ampliado nos Simpósios, garantindo, sobretudo, sua expansão e regular periodicidade.

Importa destacar que o Núcleo paulista, fundado em 04 de julho de 1962, tendo como sede a Faculdade de Filosofia, Ciências e Letras da USP, teve sua diretoria composta essencialmente por professores uspianos, vanguarda do pensamento intelectual daquele contexto. Diferentemente da entidade nacional, o Núcleo Regional apresentaria um Conselho Consultivo que, no caso paulista, teria a função de "[...] opinar sôbre as propostas de admissão de professores associados, bem como, quando solicitada, coadjuvar o Diretor na programação dos trabalhos do NRSP ${ }^{12}$." (BOLETIM INFORMATIVO, n. 1, 1962, p.11).

$\mathrm{Na}$ já referenciada primeira edição do Boletim Informativo, foi publicado o Regulamento do Núcleo Regional de São Paulo - NRSP. Neste documento, destacam-se os objetivos que corroboravam e ampliavam os escopos da Associação Nacional:

a) debate de problemas atinentes ao aperfeiçoamento do ensino das disciplinas históricas, bem como ao exercício do magistério em nível superior; b) o incentivo ao estudo, pesquisa e divulgação de assuntos de História; c) a preservação das fontes e manifestações culturais que se relacionem com os estudos históricos; d) a colaboração nos Simpósios promovidos pela APUH e e) a defesa dos direitos e legítimos interesses do Magistério superior de História (BOLETIM INFORMATIVO, n. 1, 1962, p. 10).

Ainda não estava prevista, neste Regulamento, a realização de Encontros Estaduais pelo Núcleo. Encontravam-se normalizadas, apenas, as reuniões de natureza administrativa, cuja função seria apresentar o relatório anual e eleger a nova diretoria e as reuniões culturais "[...] reservadas à apresentação de comunicações concernentes aos objetivos e às atividades socais, efetuando-se em

12 Composição da primeira diretoria - diretor: Eurípedes Simões de Paula, secretário: Raul de Andrada e Silva e tesoureiro: Padre Carl Valeer Frans Laga. Composição do primeiro Conselho Consultivo: Eduardo d'Oliveira França, Madre Leda Maria Rodrigues e Jeanne Berrance de Castro (BOLETIM INFORMATIVO, 1962, p. 8). 
datas marcadas pela Diretoria" (BOLETIM INFORMATIVO, n. 1, 1962, p. 11).

De acordo com a publicação no Diário Oficial do Estado, a 09 de setembro de 1976, em homenagem ao $15^{\circ}$ aniversário da ANPUH, os Encontros Regionais foram idealizados pelo Prof. Odilon Nogueira de Mattos e visavam ao estudo da História de São Paulo. ${ }^{13}$ Mais do que promover os Encontros que encetariam as discussões a serem aprofundadas a nível nacional, os Núcleos desempenhariam a função de estabelecer um contato mais direto com seus associados, sobretudo, pela concepção de projetos, grupos, seminários e publicações científicas, com intuito de aproximar os pesquisadores e ampliar os debates sobre as mais diferentes temáticas.

Uma importante fonte periódica, o Boletim do Historiador $^{14}$ auxilia na identificação das ações empreendidas pelo Núcleo paulista, nos anos 1990, ao focar na relação estabelecida com o ensino. No contexto em que a universidade passou a compreender a disciplina de História como um campo de conhecimento autônomo, por influência de paradigmas historiográficos externos e do próprio debate brasileiro das décadas anteriores, o NRSP pensou em diferentes meios de amparo e enriquecimento da disciplina, entre elas, a formação continuada para professores da rede pública de ensino.

Apresentado como proposta e aprovado pelo conselho do NRSP, em 1990, o "Projeto de Formação Permanente do Professor" foi uma das primeiras iniciativas do Núcleo paulista na área de ensino.

\footnotetext{
${ }^{13}$ Recortes de Jornal. Diário Oficial do Estado, 9 set. 1976. Disponível em: CAPH Centro de Apoio à Pesquisa em História Sérgio Buarque de Holanda. CPH/DH Projeto Memória da FFCL/ FFLCH-USP. Arquivo do Prof. Dr. Eurípedes Simões de Paula.

${ }^{14}$ Esta publicação, de periodicidade regular, teve efetividade e abrangência entre 1991 a 2002, apresentado um corpus documental de 26 edições localizadas, estando ausentes os números 10, 18, 19 e 20.
} 
Segundo os objetivos expressos, seria estabelecida uma parceria com a Secretaria Estadual de Educação e com as universidades paulistas para que os professores de História de $1^{\circ}$ e $2^{0}$ graus recebessem formação continuada no intuito de atualizar os conhecimentos e repensar a prática pedagógica. A professora Helenice Ciampi (2000), idealizadora do projeto, detalhou seus desígnios:

Durante dois anos, os professores selecionados terão sua carga horária semanal reduzida, para poderem participar das atividades programadas cursos e encontros para acompanhamento e orientação do trabalho escolar e elaboração do material didático. Nos primeiros três semestres letivos o Projeto possibilitará ao professor da rede pública a opção por disciplinas oferecidas na graduação pelos departamentos de História das universidades envolvidas no projeto, na qualidade de aluno especial. Paralelamente às aulas formais, haverá encontros, a cargo dos professores da Prática de Ensino, auxiliados por monitores (BOLETIM DO HISTORIADOR, n. 01, 1991, p. 02).

Entretanto, este plano e trabalho, assim como outros, arquitetado no interior de uma Associação de cunho fundamentalmente político, possuiu um caráter intermitente, experimentando episódios de maior e menor abrangência e atuação. Isso se deveu, entre outros aspectos, aos rumos seguidos pelas diretorias que ascendiam à gestão do Núcleo em diferentes conjunturas. A proposta de oferecer uma formação continuada aos professores da rede pública nasceu em um contexto em que o NRSP esteve representado por professores diretamente engajados na História disciplinar.

Entre os anos de 1990 a 1992, a então diretora Zilda Márcia Gricoli Iokoi, em conjunto com Helenice Ciampi e John Monteiro, agiu em outras frentes relacionadas ao ensino como, por exemplo, no oferecimento de cursos para professores da rede municipal paulistana, em parceria com a PUC-SP, e cursos de História da América, oferecidos à rede estadual com a participação de docentes das universidades paulistas. Além disso, foram responsáveis pela criação, no segundo semestre de 1991, do Grupo Pesquisa em Ensino, coordenado pela professora Helenice.

Nas páginas do Boletim do Historiador, avulta-se o desempenho abrangente e duradouro deste Grupo, cuja finalidade era o estímulo às 
reuniões de estudo e à divulgação de trabalhos de pesquisa de seus membros. Na seção "Notícias do Núcleo", publicada em maio de 1992, foi expressa a efetivação de um Seminário de pesquisa, em setembro de 1991, na cidade de São Vicente-SP, que contou com a presença majoritária de professores do $1^{\circ}$ e $2^{\circ}$ graus para debater questões teórico-metodológicas da disciplina (BOLETIM DO HISTORIADOR, n. 4, 1992, p. 2). Até o ano de 1994, durante o XII Encontro Regional de História - Cultura, memória e poder, realizado na cidade de Campinas-SP, o grupo permanecia atuante, abordando temas relativos à pesquisa em ensino.

$\mathrm{Na}$ ocasião desse encontro, os professores do $1^{\circ}$ e $2^{\circ}$ graus solicitaram ao Núcleo paulista o oferecimento de cursos de atualização (BOLETIM DO HISTORIADOR, n.11, 1994, p. 3), o que pressupõe a interrupção das ações do "Projeto de Formação Permanente do Professor". Possivelmente, a dificuldade em levar adiante esta iniciativa esteve relacionada à operacionalidade, já que uma das preocupações apontadas na segunda edição do Boletim do Historiador foi o imperativo de vinculá-la a um projeto de extensão, o que traria recursos financeiros para que as três universidades envolvidas, PUC-SP, USP e UNESP, pudessem executar os objetivos propostos sem onerar o público-alvo (BOLETIM DO HISTORIADOR, n. 2, 1991, p. 3).

A escassez de ações voltadas à formação continuada se justificou, também, pela diminuta inciativa das Secretarias de ensino estadual e municipais em abonarem a falta dos docentes participantes de encontros e reuniões com a entidade. Em mais de uma ocasião, o periódico analisado revelou essa realidade, sobretudo após o avanço das políticas hegemônicas de cunho neoliberal no cenário da educação paulista: "[...] Os professores da rede pública foram prejudicados pela falta de apoio das Secretarias de Educação do Município e Estado de São Paulo que não possibilitaram a dispensa de ponto" (BOLETIM DO HISTORIADOR, 1996, n.16. p. 1).

De tal forma, as diretorias que sucederam a esta gestão não publicaram nas páginas do Boletim a intenção de levar adiante outro projeto com as mesmas características. Ao longo dos anos, outras preocupações se 
tornaram mais urgentes do ponto de vista dos membros diretores empossados, cujo engajamento político era variável e obedecia a questões de ordem acadêmica e conjuntural. Vale ressaltar que, entre os anos de 1990 a 1996, a diretoria foi composta por pelo menos um intelectual diretamente ligado ao ensino de História, entretanto, a gestão mais propositiva e atuante nessa área foi a de 1990-1992, inclusive pela elaboração e execução do próprio Boletim do Historiador.

Quando John Monteiro assumiu a direção da entidade, em outubro de 1992, ao lado de Circe Bittencourt e Marisa Saenz Leme, houve o delineamento de possíveis projetos dedicados à integração da licenciatura e bacharelado e à pesquisa na área da disciplina escolar. O edital publicado pela diretoria em ascensão revelou a sobrevivência do ideal de criação de cursos de formação contínua e à distância para professores do $1^{0}$ e $2^{\circ}$ graus. Objetivou-se, em um sentido mais amplo, articular um centro de referência para a pesquisa sobre o ensino de História no Estado, com a criação de um banco de dados e linha de publicação (BOLETIM DO HISTORIADOR, 1992, n. 6. p. 1).

A materialização de parte desses ideais se deu em fevereiro de 1993, quando John Monteiro, em uma seção intitulada "Um novo projeto para o núcleo", ante a falta de ações consistentes, contínuas e sistemáticas sobre ensino, propôs a criação do projeto Pesquisa e Ensino de História no Estado de São Paulo (Diagnóstico e Perspectivas para o Futuro), cujo objetivo seria

[...] estabelecer uma base material, administrativa e de informações para um trabalho permanente dentro do Núcleo, com o fito de atender efetivas necessidades da comunidade de historiadores e criar condições mínimas para uma atuação de real impacto sobre futuras políticas de ensino e pesquisa na área (BOLETIM DO HISTORIADOR, 1993, n. 7. p. 1).

No entanto, as edições que se sucederam a esta não puderam revelar a continuidade de tais ações, fato que pressupõe seu abandono. Além disso, John Monteiro, idealizador do projeto, não voltou a assumir funções na frente diretora nos anos subsequentes, o que corrobora, mais uma vez, para a compreensão do caráter intermitente de muitos projetos e iniciativas desenvolvidas pelo Núcleo paulista nos anos de 1990. 
Se estabelecer uma relação direta com os professores de $1^{\circ}$ e $2^{\circ}$ não foi uma ação exequível para a maioria das gestões analisadas, posicionar-se criticamente em relação ao avanço das políticas de cunho neoliberal no cenário educacional brasileiro, foi. Como uma entidade historicamente combativa, ao longo dos anos de 1990, a ANPUH-SP empenhou-se em contestar nas páginas de seu Boletim as diretrizes que conduziram as reformas para profissão do historiador e para o professor de História, bem como a escola pública e o ensino da disciplina.

Entre os assuntos mais presentes em colunas e sessões do Boletim do Historiador, estavam, a nível nacional, a instalação dos Parâmetros Curriculares Nacionais - PCNs, a avaliação dos livros didáticos promovida pelo MEC e a reestruturação das escolas e universidades públicas. No cenário paulista, em particular, as preocupações estiveram relacionadas, no início dos anos 1990, à implementação da "Escola Padrão" e, nos anos finais dessa década, à reestruturação das escolas sob a lógica neoliberal que preconizava, além da diminuição da carga horária escolar e extinção de classes, o paulatino processo de municipalização.

Com a chegada dos anos 2000 e advento da comunicação online, o Boletim do Historiador veio perdendo abrangência entre os associados. Pelo alto custo que representavam, as publicações impressas da ANPUH foram, paulatinamente, sendo substituídas pela comunicação virtual ${ }^{15}$. Contudo, 0 ideal de proteção ao ensino de História continuou presente em Encontros, Simpósios e publicações. Desde sua criação, nos anos de 1960, até os dias atuais, a ANPUH nacional e o Núcleo paulista, em particular, constituem-se como espaço para frutíferas discussões e proposições para a História em seus três níveis de ensino.

\section{Referências}

15 Como expresso na edição de 2002: "O alto custo (para as condições da entidade) da correspondência escrita, pelo correio, nos leva a utilizar, cada vez mais, os recursos do nosso site e dos e-mails, para nos comunicarmos com nossos associados. Assim, pedimos, aos que ainda não fizeram que informem seus e-mails e também que atualizem seus endereços." (BOLETIM DO HISTORIADOR, ano 11, 2002, p. 1). 
ASSOCIAÇÃO NACIONAL DE HISTÓRIA - ANPUH. Disponível em: <https://anpuh.org.br>. Acesso em: 10/10/2017.

BITTENCOURT, Circe Maria Fernandes. Ensino de história: fundamentos e métodos. 3. ed. São Paulo: Cortez, 2009.

BOLETIM DO HISTORIADOR. São Paulo: ANPUH-SP, 1991-2002. Trimestral.

BOLETIM DA ANPUH, São Paulo: ANPUH, n. 1, 1993.

BOLETIM INFORMATIVO. Marília: Associação dos Professores Universitários de História - APUH. ano 01, n. 01, janeiro-outubro de 1962.

BOLETINS. In: HOUAISS, Antonio; VILLAR, Mauro de Salles. Dicionário Houaiss de Língua Portuguesa. Rio de Janeiro: Objetiva, 2004.

CANABRAVA, Alice Piffer. A associação nacional dos professores universitários de História. Revista Brasileira de História. n. 01, mar. 1981.

CIAMPI, Helenice. A história pensada e ensinada: da geração das certezas à geração das incertezas. São Paulo: EDUC, 2000.

CORDEIRO, Jaime Francisco. A história no centro do debate: as propostas de renovação do ensino de História nas décadas de setenta e oitenta. São Paulo: Cultura Acadêmica, 2000. (Coleção Pedagogia).

COSTA, Emília Viotti da. Globalização e reforma universitária: a sobrevivência do MEC-Usaid. In: LAZZARI, Raquel Leite Barbosa (Org.). Trajetórias e perspectivas da formação de educadores. São Paulo: UNESP, 2004. p. 35-48.

DE LUCA, Tânia Regina. História dos, nos e por meio dos periódicos. In: PINSKY, Carla Bessanezi. Fontes históricas. 3. ed. São Paulo: Contexto, 2014. p. 111-154.

DIÁRIO DE MINAS. Editorial. Belo Horizonte, 01-05 set 1973.

FENELON, Déa Ribeiro. A formação do profissional de história e a realidade do ensino. Cadernos Cedes. Campinas, n. 8, 1985.

FONSECA, Selva Guimarães. Caminhos da história ensinada. 9. ed. Campinas: Papirus, 2006.

GERMANO, José Willington. Estado militar e educação no Brasil. 5. ed. São Paulo: Cortez, 2011.

GHIRALDELLI JÚNIOR, Paulo. História da educação. São Paulo: Cortez, 1990. (Coleção Magistério. Série formação de prodessor). 
GLEZER, Raquel. A fundação da revista. Revista Brasileira de História. n. 1, mar. 1981.

LAPA, José Roberto do Amaral. A história em questão: historiografia brasileira contemporânea. Petrópolis, Vozes, 1976.

SILVA, Marcos Antonio. Apresentação. Revista Brasileira de História, v. 9, n. 19, set./fev. 1989/1990.

SIMPÓSIO DE PROFESSÔRES DE HISTÓRIA DO ENSINO SUPERIOR EM 1961, 1., 1962, Marilia. Anais... Marilia, 1962. p. 287-288. Disponível em: <http://anais.anpuh.org/wp-content/uploads/ANPUH.S01.pdf>. Acesso em: $10 / 10 / 2017$.

SIMPÓSIO NACIONAL DA ASSOCIAÇÃO DOS PROFESSORES UNIVERSITÁRIOS DE HISTÓRIA, 9., 1979, São Paulo. Anais... São Paulo, 1979. Disponível em: <http://anais.anpuh.org/wp-content/ uploads/ANPUH.S09.pdf>. Acesso em: 21/07/2018

SIMPÓSIO NACIONAL DE PROFESSORES UNIVERSITÁRIOS DE HISTÓRIA, 6., 1973, São Paulo. Anais... São Paulo, 1973. Disponível em:

<http://anais.anpuh.org/wp-content/uploads/ANPUH.S06.pdf>. Acesso em: 21/07/2018. 